\title{
Shape It Up: A School-Based Education Program to Promote Healthy Eating and Exercise Developed by a Health Plan in Collaboration With a College of Pharmacy
}

\author{
Saira Jan, MS, PharmD; Carina Bellman, BA; Joseph Barone, PharmD, FCCP; \\ Lois Jessen, MS, PharmD; and Marilyn Arnold, MPH, ScD
}

\begin{abstract}
BACKGROUND: Childhood obesity is an intensifying public health problem that affects millions of U.S. children. Obesity leads to the development of health conditions such as hypertension, diabetes, gastroesophogeal reflux disease, depression, and hypercholesterolemia. The increasing prevalence of these conditions among U.S. children is reflected in increased use of medical services and medications in both childhood and adulthood.
\end{abstract}

OBJECTIVE: To assess the preliminary results of the effectiveness of Shape It Up, a school-based obesity prevention program developed and implemented by the Ernest Mario School of Pharmacy at Rutgers University in conjunction with Horizon Blue Cross Blue Shield of New Jersey, with the goal of using these results to help improve the program.

METHODS: Program activities and materials included an interactive workshop, an activity book and family guide, posters, a website, and educational field days. The Shape It Up program not only delivered a positive message about eating healthful food but also modeled fruit and vegetable consumption during the interactive workshops and distributed fruits and vegetables as prizes. During the 2004-2005 and 2005-2006 school years, Shape It Up was delivered to 89,736 children at 257 New Jersey elementary schools. Pre-intervention and post-intervention surveys were administered to a convenience sample of 6,421 students at 49 participating schools. Attitudes were measured using a 6-point Likert-type graphic face scale (smiles positive, frowns negative) and analyzed for statistical significance of pre-intervention to post-intervention change using paired t-tests.

RESULTS: After exposure to the Shape It Up program, children reported higher levels of knowledge $(P<0.001)$ and positive attitudes $(P<0.001)$ about healthy eating and exercise compared with the baseline survey results. In a question to gauge satisfaction with the program, $54.9 \%$ of children surveyed gave the program the highest possible rating, and overall, $91.7 \%$ selected 1 of the 3 response categories toward the positive end of the 6-point scale.

CONCLUSION: Shape It Up appears to have had a positive impact on children's knowledge and attitudes toward exercise and healthy eating. Additional research employing a comparison group is needed to assess the program's impact.

J Manag Care Pharm. 2009;15(5):403-13

Copyright $\odot$ 2009, Academy of Managed Care Pharmacy. All rights reserved.

\section{What is already known about this subject}

- Data from the most recent National Health and Nutrition Examination Survey (NHANES 2003-2006) indicate that $16.3 \%$ of children and adolescents between the ages of 2 and 19 years old were obese (body mass index at or above the 95th percentile) and $31.9 \%$ of children were overweight (body mass index at or above the 85 th percentile)

- Obesity, in turn, increases the risk for the development of several health conditions and diseases, including hypertension, diabetes, gastroesophogeal reflux disease, depression, and hypercholesterolemia.

\section{What this study adds}

- The Ernest Mario School of Pharmacy at Rutgers University partnered with Horizon Blue Cross Blue Shield of New Jersey to develop Shape It Up, a school-based program to promote healthy eating and exercise habits among elementary school children. The program was delivered to more than 89,736 children attending 257 New Jersey elementary schools during 2 consecutive school years.

- In a survey administered in 49 schools to 6,421 children in grades 2 through 5, correct responses to a set of 6 knowledge questions about healthy eating and exercise increased from $59.4 \%$ at baseline to $82.6 \%$ after exposure to the program $(P<0.001)$.

- Responses to 3 attitude questions indicated an increase in positive attitudes towards healthy eating and exercise after exposure to the program $(P<0.001)$

$\mathrm{O}$ besity is an intensifying public health problem worldwide In the United States, approximately two-thirds of adults and nearly one-third of children are either overweight or obese by government standards., ${ }^{1,2}$ The National Institutes of Health standards for overweight and obesity for adults are based on body mass index (BMI). Because BMI is a less reliable measure of overweight/obesity in growing children than in adults, both the International Obesity Task Force and the Centers for Disease Control (CDC) favor using gender- and age-based percentiles of BMI as measures of childhood overweight and obesity. ${ }^{3}$ Thus, in this report, we use the term "overweight" to refer to children with an age- and gender-based BMI at or above the 85th percentile but below the 95th percentile. The term "obese" describes children 
with an age- and gender-based BMI at or above the 95th percentile. We use the term "overweight/obese" to refer to children with an age- and gender-based BMI at or above the 85th percentile.

Overweight and obese children are at risk for a number of health complications. Most already have at least 1 major risk factor for heart disease, and many suffer from serious health conditions once considered rare in children, such as fatty liver, gallbladder disease, high blood pressure, orthopedic problems, and sleep apnea.,5 They are more likely to require surgery and to suffer higher rates of surgical complications than children of normal weight. ${ }^{6}$ Obese children are twice as likely as children of normal weight to develop diabetes. ${ }^{7}$ Overweight/ obese children are also at high risk for psychosocial problems. Perceived overweight status has been significantly associated with suicidal thoughts and actions among female middle school children. ${ }^{8}$ In a study of weight status and quality of life, children classified as obese reported quality of life levels that were lower than those of healthy children and similar to those with a diagnosis of cancer. ${ }^{9}$

Weight problems are persistent. Seventy percent of children who are obese during adolescence become obese adults. ${ }^{10,11}$ Carrying excess weight into adulthood puts today's overweight/ obese children at elevated risk for 4 of the 10 leading causes of death (heart disease, stroke, cancer, and diabetes), as well as arthritis, renal disease, and other serious health problems. ${ }^{11,12}$

Obesity has steep economic costs. In 1998, U.S. expenditures for medical services, such as physician office visits and hospitalizations, related to overweight and obesity totaled an estimated $\$ 78.5$ billion, or $\$ 92.6$ billion in 2002 dollars. ${ }^{13}$ Among children aged 6-17 years, annual obesity-related hospital costs climbed from $\$ 35$ million in 1979-81 to $\$ 127$ million in 1997-99 as the number of obesity-related hospital days more than doubled, reaching 310,000.14 Among children, hospital discharges for primary diagnosis of obesity increased by 197\% during that period, while discharges for the obesity-related conditions of sleep apnea and gallbladder disease rose by $436 \%$ and $228 \%$, respectively. ${ }^{14}$ Obesity accounts for just over $9 \%$ of U.S. health care spending. ${ }^{13}$

Researchers at the Johns Hopkins University Bloomberg School of Public Health's Center for Human Nutrition project that by 2030 more than $85 \%$ of U.S. adults could be overweight or obese if current trends continue and that total health care costs attributable to overweight and obesity could range from $\$ 860.7$ to $\$ 956.9$ billion, consuming 1 of every 6 health care dollars. ${ }^{15}$ The emergence and continuing intensification of this complex public health problem has been linked with a variety of changes in the physical, social, and cultural environments. Shifts in eating habits, exercise habits, and media usage patterns have all been implicated in rising rates of overweight/obesity.

The past several decades have brought major changes in what, and how much, Americans eat. Food portion sizes have increased in restaurants and at home, resulting in increased calorie intake. For example, from 1977 to 1996, the caloric content of an aver- age hamburger served in the United States increased from 389 calories to 486 calories. ${ }^{16}$ American children are eating more than the recommended amount of fat, including saturated fat. Between 1977-78 and 2001-02, pizza intake quadrupled (413\% increase), candy intake nearly doubled (180\% increase), and consumptions of savory-grain snack foods, such as tortilla chips, corn chips, and pretzels, more than tripled among children aged 6-11 years. ${ }^{17}$ High-fat fast foods such as fried potatoes are now available in multiple venues, including schools and hospitals. An estimated 30\% of American children eat some kind of fast food on a typical day. ${ }^{18}$

Fruit and vegetable consumption among children is well below recommended levels. In their analyses of the U.S. Department of Agriculture's (USDA) Continuing Survey of Food Intakes by Individuals (CSFII) data from 1994-96 and 1998, applying USDA Food Guide Pyramid (FGP) standards for fruit and vegetable intake, Enns et al. found that $80 \%$ of children aged $6-11$ years ate fewer than the recommended number of servings of vegetables and that $76 \%$ of girls and $77 \%$ of boys in this age group consumed less than the recommended number of servings of fruit. 19,20 Their analyses of 1994-96 CSFII data for adolescents aged $12-19$ years indicated that $74 \%$ of girls and $67 \%$ of boys consumed fewer than the recommended servings of vegetables by FGP standards Just $18 \%$ of girls and $14 \%$ of boys had diets that met the FGP recommendations for fruit consumption based on their caloric intake. ${ }^{21}$ Youth Behavioral Risk Surveillance System findings indicate that fully $79.9 \%$ of high school students had eaten less than 5 servings of fruits and vegetables per day during the past week in 2005.22

In 2005, the USDA released new dietary guidelines including MyPyramid, a revision of the FGP. ${ }^{20,23}$ The 2005 guidelines, which are the most current version, call for a recommended intake of 9 servings of fruits and vegetables per day for a reference 2,000 calorie diet. These guidelines also recommend weekly intake levels for 5 subgroups of vegetables as follows: dark green vegetables ( 3 cups), orange vegetables ( 2 cups), legumes ( 3 cups), starchy vegetables ( 3 cups), and other vegetables (6.5 cups). Based on their analyses of the 1999-2000 National Health and Nutrition Examination Survey (NHANES) data, Guenther et al. found that overall, just $40 \%$ of Americans consumed 5 or more 1/2-cup servings of fruits and vegetables per day, the prevailing FGP standard during their data collection period. ${ }^{24}$ Broken down by sex-age groups, the reported percentages of children and adolescents consuming fruits and vegetables at the then-current FGP recommended levels were as follows: girls aged 4-8 years (9.8\%), girls aged $9-13$ years (19.8\%), girls aged $14-18$ years (28.3\%), boys aged $4-8$ years $(13.8 \%)$, boys aged $9-13$ years $(17.6 \%)$, and boys ages 14-18 years (37.0\%). Mean daily intake levels of fruit, total vegetables, and 4 of the 5 subgroups of vegetables were below recommended levels for all sex-age groups; however, intake of the starchy vegetables (such as white potatoes, corn, green peas, and lima beans) was above recommended levels for 11 of 15 
sex-age groups. ${ }^{24}$ The mean intakes of dark leafy green vegetables, orange vegetables, and legumes were less than one-third of recommended levels. ${ }^{24}$

In a recent analysis of the 1999-2002 NHANES 1-day food intake data applying 2005 dietary guidelines, Lorson et al. found that among children aged $6-11$ years, $74.1 \%$ failed to meet the recommendations for fruit intake, and $83.8 \%$ failed to meet the recommendations for vegetable intake. Among adolescents aged $12-18$ years, $80.5 \%$ failed to meet the recommendations for fruit intake, and $89.5 \%$ failed to meet the recommendations for vegetable intake. In that study, the leading source of vegetables for U.S. children aged 2-19 years was french fries, and the leading source of total fruit was fruit juice. ${ }^{25}$

Soda intake among U.S. children and teens has risen while milk consumption has decreased. ${ }^{19,26,27}$ Comparing dietary intake data from 3 national USDA surveys, French et al. found that the mean daily intake of soda among U.S. children aged 6-17 years more than doubled from $1977 / 78$ to $1994 / 98 .^{27}$ According to NHANES data, soda was the top food contributing to energy intake among Americans in 1988-1994 and in 1999-2000. ${ }^{28}$

Most U.S. children get far less than the recommended 60 minutes of moderate physical exercise per day. Although 36 states mandate physical education for elementary school students, only 2 states require participation at or above the 150 minutes-per-week level recommended by the American Heart Association. ${ }^{29}$ A recent National Institute of Child Health and Human Development study found that most children participate in just 25 minutes per week of moderate to vigorous physical activity in physical education classes. ${ }^{30}$ The CDC's Youth Media Campaign Longitudinal Survey found that $61.5 \%$ of children aged 9-13 years do not participate in any organized physical activity during their non-school hours, and $22.6 \%$ engage in no free-time physical activity at all. ${ }^{31}$

Many studies have linked rising childhood obesity rates with the amount of time that children spend on "screen media" activities, such as watching television, playing video games, and surfing the Internet. A recent national survey found that, on average, U.S. children aged 8-18 years spend more than 5 hours per day on screen media activities, including 3 hours and 51 minutes of television watching. ${ }^{32}$ Research on the reasons for the positive correlation between children's screen media time and overweight/obesity has been inconclusive, but the negative influence of advertising on healthy food choices, displacement of physical activity, and the impact of extended sedentary activity on metabolic rate and snacking consumption patterns have been implicated as possible factors. ${ }^{33}$

Experts agree that prevention is the key to reversing the childhood overweight/obesity epidemic. ${ }^{34}$ Schools represent a prime venue for obesity prevention interventions and policies because children spend a great portion of their day in these educational environments. These settings facilitate the reinforcement of healthy eating habits and physical activity through established programs, such as lunches and physical education classes. One of the immediate childhood obesity prevention recommendations proposed by the Institute of Medicine is to "develop, implement, and evaluate innovative pilot programs for both staffing and teaching about wellness, healthful eating, and physical activity." 35 This paper presents an exploratory analysis of the implementation and impact of one such innovative program, Shape It Up, a health education intervention to promote knowledge and positive attitudes toward exercise and healthy eating among elementary school children.

\section{Methods}

\section{Participants and Study Design}

Shape It Up was delivered to 89,736 students in 257 New Jersey elementary schools. All 640 New Jersey school districts were invited to participate in Shape It Up, and 400 schools from different regions of the state requested the program, exceeding capacity to serve all interested schools during a single school year. Schools were thus enrolled on a first-come, first-served basis. The program was delivered to 150 schools during the 2004-05 school year, and the remaining schools were placed on a waiting list. During the 2005-06 school year, the Shape It Up program was delivered to an additional 107 schools that were selected at random from the program's waiting list. Participating schools were from multiple school districts located in all 3 regions of the State of New Jersey.

The study used a single-sample pre-intervention and postintervention design to assess the impact of the Shape It Up program on children's knowledge and attitudes towards exercise and healthy eating. These outcomes were assessed using questionnaires administered at baseline (pre-intervention) and about 2 weeks following exposure to the program (postintervention). The results reported here are for a convenience sample of 6,421 students in grades 2 through 5, enrolled in 49 of the 107 schools who received the program during the 2005-06 school year, for whom we had both a pre-intervention and post-intervention survey. We excluded duplicate surveys (166), surveys for which there was no matched pretest survey $(2,976)$ or post-test survey $(3,045)$, blank surveys (145), and pre-intervention/post-intervention survey combinations that indicated inconsistencies in grade level (101) or gender (879). Our decision rule for gender inconsistencies was to exclude both individual students with pre-intervention/post-intervention gender mismatches and entire classrooms for which there were 3 or more gender inconsistencies, due to concerns about the proper handling of the survey administration process by teachers in those classrooms. We excluded surveys from all students in grade 1 (194) because of literacy concerns and small numbers. We also excluded surveys from all students in grade 6 (211) because of small numbers and concerns about differences 
between school districts, many of which configure elementary schools as grades K-5 only. The study was approved by the Rutgers University Institutional Review Board for the Protection of Human Subjects in Research and by the Horizon Blue Cross Blue Shield of New Jersey Privacy Board.

\section{Intervention}

The Shape It Up program was a collaboration between the Ernest Mario School of Pharmacy at Rutgers University and Horizon Blue Cross Blue Shield of New Jersey, funded by a grant from sanofiaventis. The broad goal of the program was to increase awareness about the importance of healthy eating and exercise among New Jersey elementary school children, their school communities, and families, with the purpose of decreasing childhood obesity. Key program learning objectives included the following: (a) determine healthy portion sizes, (b) explain the Food Pyramid, (c) identify the health benefits of eating a variety of fruits and vegetables, (d) recognize the disadvantages of excess soda consumption and the benefits of milk and water consumption, (e) recognize the health benefits of exercise for the heart, and (f) describe how saturated fat affects the heart. The workshop comprised 6 segments that corresponded to each learning objective (Table 1).

The program's central activity was one 60-minute interactive workshop presented in school auditoriums and cafeterias to groups of approximately 100 students. The workshop was designed in accordance with tenets of social cognitive theory and complied with requirements of the New Jersey Core Health curriculum. Workshop presenters used a variety of props and demonstrations to gain audience attention and drive home concepts in a visually striking manner. For example, to dramatize how saturated fat can clog arteries, presenters used solid vegetable shortening (simulating plaque) to coat the inside of a large length of white plumbing pipe (arteries), through which they then attempted to pass water that had been dyed bright red (blood). The workshop's vivid format was designed to get children's attention and to counter their exposure to media messages that promote high fat and low nutrition foods.

Workshops were presented by trained volunteers drawn from Ernest Mario School of Pharmacy graduate students, fellows, and faculty. Presenters completed a training session and worked in teams that included at least 1 pharmacy school faculty member. Monthly training sessions for presenters reinforced the quality and consistency of program delivery.

Students who attended a Shape It Up workshop also received a Shape It Up booklet to take home and share with family members. The booklets were designed to reinforce the main learning objectives and included a website address that parents or guardians could visit for further information. Schools received Shape It Up posters that presented key intervention messages for display in classrooms, school hallways, and cafeterias.

As a follow-up to the in-school intervention, a series of voluntary Shape It Up educational field days were held. These events, which served more than 2,000 children, were held in sports stadiums located near the participating schools and involved a full day of participation in active games based on the Shape It Up program themes, along with consumption of healthful foods and beverages. The purpose of the field days was to reinforce program messages. All children enrolled in schools who participated in the Shape It Up program were eligible to attend the field day events. All field days were conducted after the post-intervention questionnaire had been administered.

\section{Questionnaires and Data Collection Procedures}

The pre-intervention and post-intervention questionnaires included 11 closed-ended items (core questions) to measure demographics, knowledge, and attitudes about healthy eating and exercise (Figure 1). Knowledge questions allowed for "don't know" responses to discourage guessing. Attitude questions used a 6-point Likert-type graphic face scale based on the Wong scale. ${ }^{36}$ In addition to the 11 core questions, the pre-intervention questionnaire included 5 closed-ended behavioral measures of soda consumption, exercise, eating breakfast, and media usage. The behavioral questions were included in the pre-intervention survey but not the post-intervention survey for the purpose of planning potential subsequent interventions. Also, from a health behavior perspective, measuring changes in behavior from preintervention to post-intervention would not have yielded meaningful results given the short time (about 2 weeks) between the program workshop and post-intervention data collection. The post-intervention questionnaire included the 11 core questions plus a question to measure student satisfaction with the Shape It Up Program as well as space for open-ended comments.

Both questionnaires were pilot tested on a sample of 50 children aged 8 to 10 years to improve content validity. Readability was assessed using the Flesch-Kincaid Reading Ease Scale, which scores documents on a 100-point scale with higher scores indicating greater readability. ${ }^{37}$ The Flesch-Kincaid Reading Ease ratings for the questionnaire items were as follows: 86.3 for the 11 core knowledge, attitude, and demographic questions that appeared on both the pre-intervention and post-intervention questionnaires; 82.4 for 5 behavioral questions (pre-intervention questionnaire only); and 92.4 for 2 satisfaction questions (postintervention questionnaire only).

Children completed both questionnaires in their classrooms under the supervision of their classroom teachers. The pre-intervention questionnaires were completed within 2 weeks prior to the Shape It Up workshop. The post-intervention questionnaires were completed within 2 weeks after the Shape It Up workshop.

\section{Statistical Analyses}

Data collection was conducted by The Eagleton Institute, and statistical analyses were completed by the Bloustein Center for Survey Research. Data were analyzed using SPSS v.15.0 (SPSS Inc., Chicago, IL). The 6 knowledge items were aggregated to 


\section{Shape It Up: A School-Based Education Program to Promote Healthy Eating and \\ Exercise Developed by a Health Plan in Collaboration With a College of Pharmacy}

\begin{tabular}{|c|c|c|c|}
\hline $\begin{array}{l}\text { Workshop } \\
\text { Segment Title }\end{array}$ & Key Learning Objectives & Key Behavioral Objectives & Methods/Materials \\
\hline Portion sizes & $\begin{array}{l}\text { Become more aware of portion sizes. } \\
\text { Identify healthful portion sizes of common } \\
\text { foods. }\end{array}$ & $\begin{array}{l}\text { Select and consume healthful portion } \\
\text { sizes, about the size of a tennis ball } \\
\text { and often smaller than those served at } \\
\text { restaurants and in homes. }\end{array}$ & $\begin{array}{l}\text { Modeling, audience participation. } \\
\text { Tennis balls, large sports balls. }\end{array}$ \\
\hline Food pyramid & $\begin{array}{l}\text { Recognize the main food groups. } \\
\text { Understand the concept of a balanced diet. }\end{array}$ & $\begin{array}{l}\text { Eat a balanced diet rich in grains, fruits } \\
\text { and vegetables. }\end{array}$ & $\begin{array}{l}\text { Interactive discussion, demonstrations, } \\
\text { hands-on learning materials, audience } \\
\text { participation. } \\
\text { Food Pyramid chart, paper plates, plastic } \\
\text { foods. }\end{array}$ \\
\hline Fun with fruit & $\begin{array}{l}\text { List the health benefits of eating a variety } \\
\text { of fruits. }\end{array}$ & Increase fruit consumption. & $\begin{array}{l}\text { Charting, interactive discussion, audience } \\
\text { participation. } \\
\text { Benefits of fruit chart, fresh fruits. }\end{array}$ \\
\hline $\begin{array}{l}\text { Soda versus } \\
\text { water }\end{array}$ & $\begin{array}{l}\text { Realize how much sugar is in soda. } \\
\text { Understand the importance of water/ } \\
\text { hydration for health. } \\
\text { Identify the positive health effects of } \\
\text { drinking water and eating foods with high } \\
\text { water content (fruits, vegetables). }\end{array}$ & $\begin{array}{l}\text { Limit soda intake. } \\
\text { Increase water intake. }\end{array}$ & $\begin{array}{l}\text { Demonstration, interactive discussion, } \\
\text { audience participation. } \\
\text { Water, scoop, sugar, can of soda. }\end{array}$ \\
\hline $\begin{array}{l}\text { Exercise and } \\
\text { heart health }\end{array}$ & $\begin{array}{l}\text { Link aerobic exercise with heart health. } \\
\text { View the heart as a muscle that needs } \\
\text { exercise to stay healthy. } \\
\text { Identify ways to get aerobic exercise: } \\
\text { walking, biking, etc. }\end{array}$ & Increase aerobic exercise. & $\begin{array}{l}\text { Modeling, group exercise, audience } \\
\text { participation. } \\
\text { Heart rate chart. }\end{array}$ \\
\hline Healthy arteries & $\begin{array}{l}\text { Understand the concept of clogged arteries. } \\
\text { Realize that eating fatty foods can clog } \\
\text { arteries. } \\
\text { Identify common fatty foods: pizza, french } \\
\text { fries, chicken nuggets, etc. } \\
\text { Link healthy arteries with eating healthful } \\
\text { foods and exercise. }\end{array}$ & $\begin{array}{l}\text { Eat less fatty foods. } \\
\text { Eat more "heart healthy" foods. } \\
\text { Do more exercise. }\end{array}$ & $\begin{array}{l}\text { Demonstration, audience participation. } \\
\text { Clear plastic tube, colored water, white } \\
\text { vegetable shortening, bucket. }\end{array}$ \\
\hline
\end{tabular}

create a single knowledge outcome for each student with possible scores ranging from 0 (6 incorrect) to 6 (6 correct). The knowledge composite measure was converted to a metric from 0 to 100, where higher values indicate more correct responses; the purpose of this conversion was to allow for more intuitive results with scores conceptualized in concert with traditional classroom grading. The 3 attitudinal items measuring opinions about eating fruit, eating vegetables, and exercising, which were scored on a scale of 0 (most favorable) to 5 (least favorable), were summed to create a single attitudinal outcome. The resulting attitudinal scale ranged from 0 (positive on all 3 questions) to 15 (negative on all three questions). The attitudinal composite measure was then converted to a metric from 0 to 100, where 100 indicates positive attitude to allow for more intuitive interpretation of the results. Paired t-tests were completed to compare the mean values pre-intervention and post-intervention on knowledge and attitude outcomes. The critical value for determining statistical significance was $P=0.05$.

\section{Results}

Of the 6,421 participating students who completed surveys, 49.9\% were males, $24.3 \%$ were second graders, $26.7 \%$ were third graders, $23.8 \%$ were fourth graders, and $25.2 \%$ were fifth graders. The mean grade level was 3.5 .

The mean number of days per week respondents reported physical exercise was 3.83 at baseline. In all, 49.8\% of respondents reported that they exercised 5 or more days per week, and $9.2 \%$ reported exercise activity 1 day per week or less (Table 2). The mean number of servings of soda consumed per day was 1 , and more than one-quarter (26.6\%) of respondents reported drinking 2 or more servings of soda per day. The mean number of hours of reported daily television, video, and digital video disc (DVD) use was 2.10, with 35.3\% of children reporting 3 or more hours per day. On average respondents reported spending 1.6 hours per day playing video/computer games, and $24.2 \%$ of children reported spending 3 or more hours per day on this activity. In all, $81.6 \%$ reported that they 
FIGURE 1 Shape It Up Questionnaire

9 CORE ATTITUDINAL AND KNOWLEDGE ITEMS (BOTH SURVEYS)

Draw a circle around the one face that best shows your feelings.

1. How do you feel about eating fruit?

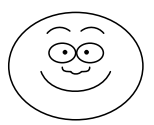

0

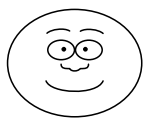

1

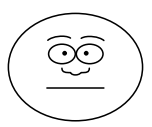

2

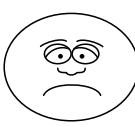

3

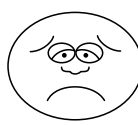

4

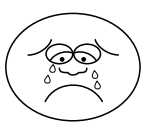

5

2. How do you feel about eating vegetables?

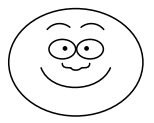

0

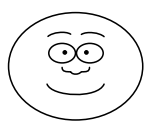

1

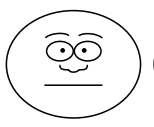

2

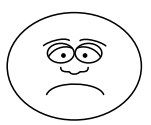

3

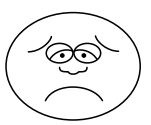

4

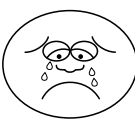

5
3. How do you feel about doing exercise?

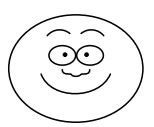

0

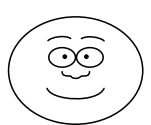

1

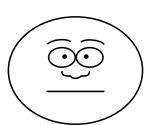

2

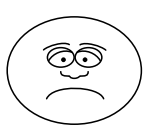

3

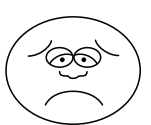

4

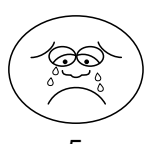

5
Check just one answer for each question.

4. The fat in food can clog the blood flow in your arteries.

$$
\square \text { True } \square \text { False } \square \text { Don't Know }
$$

5. A healthy serving size of food is the size of a tennis ball.

$$
\square \text { True } \square \text { False } \square \text { Don't Know }
$$

6. A can of regular soda has 1 teaspoon of sugar.

$$
\square \text { True } \square \text { False } \square \text { Don't Know }
$$

7. Exercise makes your heart strong.

$$
\square \text { True } \square \text { False } \square \text { Don't Know }
$$

8. Milk and water are better for you than soda.

$$
\square \text { True } \square \text { False } \square \text { Don't Know }
$$

9. How many servings of fruits and vegetables should you eat a day?

$$
\square_{1} \square 2 \quad \square_{3} \quad \square_{4} \quad \square 5 \text { or more } \square \text { Don't Know }
$$

\section{BEHAVIORAL ITEMS (PRE-INTERVENTION SURVEY ONLY)}

10. How many days a week do you exercise (play sports, dance, swim, ride your bike, take a walk)?

$$
\begin{aligned}
& \square \text { none } \\
& \square 1 \text { day per week } \\
& \square 2 \text { days per week } \\
& \square 3 \text { days per week } \\
& \square 4 \text { days per week } \\
& \square 5 \text { or more days per week }
\end{aligned}
$$

11. On most days, how many sodas (cans, bottles or cups) do you drink?

$$
\begin{aligned}
& \square \text { none } \\
& \square 1 \text { soda a day } \\
& \square 2 \text { sodas a day } \\
& \square 3 \text { sodas a day } \\
& \square 4 \text { or more sodas a day }
\end{aligned}
$$

12. On most days, how many hours do you watch TV, videos or DVDs?

$$
\begin{aligned}
& \square \text { none } \\
& \square 1 \text { hour a day } \\
& \square 2 \text { hours a day } \\
& \square 3 \text { hours a day } \\
& \square 4 \text { or more hours a day }
\end{aligned}
$$

13. On most days, how many hours do you play video games or computer games?

$$
\begin{aligned}
& \square \text { none } \\
& \square 1 \text { hour a day } \\
& \square 2 \text { hours a day } \\
& \square 3 \text { hours a day } \\
& \square 4 \text { or more hours a day }
\end{aligned}
$$

14. Do you eat breakfast every day?

$$
\square \text { Yes } \square \text { No }
$$

\section{DEMOGRAPHIC ITEMS (BOTH SURVEYS)}

15. Are you a boy or a girl?

$$
\square \text { boy } \square \text { girl }
$$

16. What grade are you in?

$$
\begin{aligned}
& \square \text { 2nd grade } \square \text { 3rd grade } \square \text { 4th grade } \\
& \square \text { 5th grade } \square \text { 6th grade }
\end{aligned}
$$

\section{OPINION ITEMS (POST-INTERVENTION SURVEY ONLY)}

Draw a circle around the one face that best shows your feelings.

12. How do you feel about the "Shape It Up" assembly?

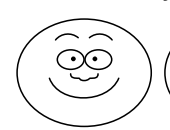

0

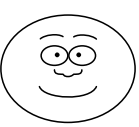

1

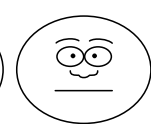

2

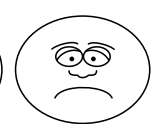

3

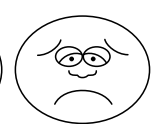

4

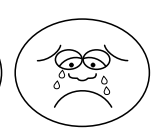

5
13. What are some of the things you learned from "Shape It Up"?

Please check to be sure you answered all the questions. Thank You! 
eat breakfast every day (data not shown).

On the 6 knowledge questions, the mean number of correctly answered questions rose from 3.6 at baseline to 5.0 after exposure to the intervention (data not shown). After the sum of 0-6 correctly answered questions was converted to the 0-100 scale, the mean score increased from 59.4 before students participated in the program to 82.6 afterwards $(P<0.001, n=6,419$; Table 3$)$. After conversion of the 3 attitudinal items (eating fruit, eating vegetables, and exercising) to the 0-100 metric, the mean attitudinal score increased from 82.1 on the pretest to 86.0 on the posttest $(P<0.001, n=6,418$; Table 4$)$.

Students reported high levels of satisfaction with the program (Table 4). In a question to gauge satisfaction with the program, $54.9 \%$ of children gave the program the highest possible rating by selecting the face with the broadest smile. Overall 91.7\% selected 1 of the 3 response categories toward the positive end of the 6-point scale.

\section{Discussion}

This study assessed the impact of an intervention to promote knowledge and positive attitudes towards healthy eating and exercise among students in grades 2 through 5 . Student responses to pre-intervention and post-intervention questionnaires indicated a significant increase in the percentage of correct responses to a series of knowledge and attitudinal questions about healthy eating and exercise.

The Shape It Up program was designed to counter the barrage of advertisements for low nutrition foods that children are exposed to on a regular basis with a vivid and compelling educational intervention promoting healthy eating. Such efforts are important because recent research indicates that children 8-12 years old are exposed to more than 7,600 television food advertisements per year, of which $44 \%$ are for candy, snacks, or fast food; just $5 \%$ of such advertisements are for fruit juice or dairy products. On average, in the course of a year, children in this age range see only 1 public service announcement on fitness or nutrition for every 48 food ads. ${ }^{38}$ Responses to behavioral questions included on the baseline survey indicated that the habits of the New Jersey children we surveyed with respect to soda consumption and media consumption were similar to those reflected in national trends. ${ }^{39}$ The Shape It Up program not only delivered a positive message about eating healthful food but also modeled fruit and vegetable consumption during the interactive workshops and distributed fruits and vegetables as prizes.

Health habits formed in childhood set the stage for adult practices. ${ }^{40-42}$ Experts agree that diagnosis and prevention at an early age is critical to curbing the obesity epidemic.43-49 Our results indicated that children exposed to the Shape It Up intervention achieved higher scores on knowledge and attitudinal questions related to the 2 behaviors cited most as key to reversing the obesity epidemic: exercise and healthy eating.

\begin{tabular}{|c|c|c|c|c|}
\hline & $\begin{array}{c}\text { Exercise }^{a} \\
\%(n=6,405)\end{array}$ & $\begin{array}{c}\text { Sodas }^{\mathbf{b}} \\
\%(\mathrm{n}=6,383)\end{array}$ & $\begin{array}{c}\text { Screen } \\
\text { Watching } \\
\%(n=6,381)\end{array}$ & $\begin{array}{c}\text { Screen } \\
\text { Playingc } \\
\%(n=6,397)\end{array}$ \\
\hline \multirow[t]{6}{*}{ one } & 2.0 & 42.4 & 7.6 & 22.3 \\
\hline & 7.2 & 33.8 & 31.6 & 36.6 \\
\hline & 10.2 & 14.2 & 25.5 & 17.0 \\
\hline & 16.7 & 4.8 & 14.3 & 8.8 \\
\hline & 14.1 & 7.6 & 21.1 & 15.4 \\
\hline & 49.8 & Inapplicable ${ }^{\mathrm{d}}$ & Inapplicable $^{\mathrm{d}}$ & Inapplicable ${ }^{\mathrm{d}}$ \\
\hline$a^{e}$ & 3.8 & 1 & 2.10 & 1.6 \\
\hline
\end{tabular}

${ }^{a}$ Number of days per week.

"Number consumed each day, highest response category = "4 or more."

"Number of hours per day; includes "TV, videos, or DVDs" (watching) or "video games or computer games" (playing); highest response category = "4 or more."

"Highest response category for questions about soda consumption, screen watching and screen playing was "4 or more."

"Total scores divided by number of children completing item.

Countering the obesity epidemic among America's children will require an ecological approach with efforts at the individual, interpersonal, organizational, community and policy levels. ${ }^{50-51}$ One of the strengths of Shape It Up was its multilevel focus that included children, their school communities, and their families. Some schools used the Shape It Up materials as a basis for developing lesson plans on nutrition and exercise. Schools that use Shape It Up in the future will not incur the costs associated with developing the program lessons and materials. Also, our experience with program delivery logistics such as recruiting, training, and scheduling volunteer presenters can be applied to streamline implementation in future sites. Another important positive feature of the Shape It Up program was that community-level partnerships between the public schools, Horizon Blue Cross Blue Shield of New Jersey, and the Ernest Mario School of Pharmacy at Rutgers University made it possible to deliver the intervention to nearly 90,000 children at no monetary cost to the schools, children, or family members.

Research indicates that being overweight is associated with increased rates of chronic disease and health care utilization among both adults and children ${ }^{6,11-14,52}$ and with use of medications to treat the associated chronic conditions, such as diabetes and hypertension. ${ }^{53,54}$ As obesity rates climb so do expenditures for the diagnosis and treatment of obesity-related conditions..$^{55}$ Moreover, there are indications that obesity can be difficult to manage and reverse..$^{56}$ The economic burden posed by obesity, coupled with spiraling health care costs, poses a substantial challenge to the U.S. health care system. ${ }^{13,15}$ Health promotion efforts such as Shape It Up that mobilize volunteer support and take a primary prevention approach to obesity are worthy of consideration as part of the solution..$^{57}$ 
Shape It Up: A School-Based Education Program to Promote Healthy Eating and

Exercise Developed by a Health Plan in Collaboration With a College of Pharmacy

TABLE 3 Pre-Intervention and Post-Intervention Knowledge Question Responses to Survey Administered to Children in Grades 2 to 5 Participating in the Shape It Up Intervention in 49 New Jersey Schools

\begin{tabular}{|c|c|c|c|}
\hline Item $(n)^{a}$ & $\begin{array}{l}\text { Pre-Intervention Responses } \\
\text { Mean [SD] }\end{array}$ & $\begin{array}{c}\text { Post-Intervention Responses } \\
\text { Mean [SD] }\end{array}$ & $P$ Value $^{\mathrm{b}}$ \\
\hline $\begin{array}{l}\text { K1. The fat in food can clog the blood flow in } \\
\text { your arteries. }(6,407)\end{array}$ & $62.4[48.4]$ & $93.9[23.9]$ & $<0.001$ \\
\hline $\begin{array}{l}\text { K2. A healthy serving size of food is the size } \\
\text { of a tennis ball. }(6,390)\end{array}$ & $15.4[36.1]$ & $90.2[29.7]$ & $<0.001$ \\
\hline $\begin{array}{l}\text { K3. A can of regular soda has } 1 \text { teaspoon of } \\
\text { sugar. }(6,396)\end{array}$ & $57.6[49.4]$ & $89.3[30.9]$ & $<0.001$ \\
\hline K4. Exercise makes your heart strong. $(6,403)$ & $93.3[25.0]$ & $97.1[16.8]$ & $<0.001$ \\
\hline $\begin{array}{l}\text { K5. Milk and water are better for you than } \\
\text { soda. }(6,409)\end{array}$ & $97.9[14.0]$ & $98.3[13.1]$ & 0.107 \\
\hline $\begin{array}{l}\text { K6. How many servings of fruits and } \\
\text { vegetables should you eat a day? }(6,374)\end{array}$ & $29.2[45.4]$ & $27.9[44.4]$ & 1.000 \\
\hline Knowledge Summary Score $(6,419)$ & $59.4[17.1]$ & $82.6[13.8]$ & $<0.001$ \\
\hline
\end{tabular}

aNumber of respondents varies because of item nonresponse.

${ }^{b}$ T-tests for paired samples.

CRepresents sum of knowledge items ( $0=$ no items correct, $6=6$ items correct), rescaled to 0-100 (e.g., 5 items correct is a score of 83.3).

\section{Limitations}

The foremost limitation of this pilot research project was its single-group design. Without a control group, we are not able to attribute the positive changes we observed in knowledge and attitudes after exposure to the Shape It Up intervention because of potential threats to internal validity.

Second, our evaluation was conducted with a small percentage of the children who received the intervention $(6,421$ out of 89,736 ). Our decision to limit our analyses to children in grades 2 through 5 reduced our original sample size. A related point is that this was a convenience sample drawn solely from self-selected schools that participated during the second year of the program. Our evaluation results are based on data collected from 49 schools, representing just $19.0 \%$ of all 257 schools that received the program. This amounts to $45.8 \%$ of the 107 schools that received the program during the 2005-06 school year. We cannot generalize our findings beyond our sample and cannot predict the impact of Shape It Up on children in other locations.

Third, there was a short time between exposure and follow-up that required us to focus on proximal learning outcomes and not on behavioral change. Nonetheless, our positive findings with respect to knowledge and attitudes are encouraging in light of the tenets of health behavior theory which indicate that that knowledge and attitude change are important precursors to behavioral change. ${ }^{58}$

Despite these limitations, our positive results suggest that the Shape It Up program merits consideration as a promising approach to addressing our nation's intensifying epidemic of obesity and overweight. Future efforts under consideration for the Shape It Up program include sustained messaging through multiple continuing related classroom activities, enhanced use of multiple channels such as the Internet, as well as intensified efforts to involve participation by children's family members.

\section{Conclusion}

After participating in the Shape It Up program, a convenience sample of New Jersey elementary school children reported higher levels of knowledge and increased positive attitudes about healthy eating and exercise. Satisfaction levels with the program were high. Although these results are promising, additional research employing a comparison group is necessary to determine the program's impact. Health plans can work effectively with schools of pharmacy to develop health intervention programs with the intent of affecting behavior in school-age children.

\section{Authors}

SAIRA JAN, MS, PharmD, is Director of Clinical Pharmacy, Horizon Blue Cross Blue Shield of New Jersey, Newark, New Jersey, and Associate Professor, Ernest Mario School of Pharmacy, Rutgers University, Piscataway, New Jersey. CARINA BELLMANN, BA, is Associate Director, Bilingual Buds, Summit, New Jersey. JOSEPH BARONE, PharmD, FCCP, is Chair of the Department of Pharmacy Practice and Administration, Ernest Mario School of Pharmacy, Rutgers University, Piscataway, New Jersey. LOIS JESSEN, MS, PharmD, is Director, Medical Information, Immunoscience, BristolMyers Squibb, Plainsboro, New Jersey; at the time of this research, she was Clinical Associate Professor and Vice Chair, Ernest Mario School of Pharmacy, Rutgers University, Piscataway, New Jersey. MARILYN ARNOLD, MPH, ScD, is Research Associate, Harvard School of Public Health, Boston, Massachusetts.

AUTHOR CORRESPONDENCE: Saira Jan, MS, PharmD, Horizon Blue Cross Blue Shield of New Jersey, 3 Penn Plaza East, PP-13Q, Newark, NJ 01705. Tel.: 973.466.6192; Fax: 973.466.4665; E-mail: Saira_Jan@horizonblue.com. 
Shape It Up: A School-Based Education Program to Promote Healthy Eating and

Exercise Developed by a Health Plan in Collaboration With a College of Pharmacy

TABLE 4 Pre-Intervention and Post-Intervention Attitudinal Question Responses to Survey Administered to Children in Grades 2 to 5 Participating in the Shape It Up Intervention in 49 New Jersey Schools

Attitude Questions (n)a

Al. How do you feel about eating fruit? $(6,414)$

\begin{tabular}{|c|c|c|c|}
\hline \multicolumn{2}{|c|}{ Pre-Intervention } & \multicolumn{2}{|c|}{ Post-Intervention } \\
\hline Response Values & $\%$ & Response Values & $\%$ \\
\hline 0-Positive & 62.6 & 0-Positive & 70.4 \\
\hline 1 & 23.7 & 1 & 19.6 \\
\hline 2 & 9.9 & 2 & 6.8 \\
\hline 3 & 2.0 & 3 & 1.1 \\
\hline 4 & 0.7 & 4 & 0.8 \\
\hline 5-Negative & 1.1 & 5-Negative & 0.8 \\
\hline \multicolumn{2}{|c|}{ Mean [SD] $0.576[0.929]^{b}$} & \multicolumn{2}{|c|}{ Mean $[S D] 0.438[0.842]^{b}$} \\
\hline 0-Positive & 27.8 & 0-Positive & 36.3 \\
\hline 1 & 25.8 & 1 & 29.0 \\
\hline 2 & 25.6 & 2 & 20.2 \\
\hline 3 & 9.2 & 3 & 6.7 \\
\hline 4 & 4.9 & 4 & 3.1 \\
\hline 5-Negative & 6.7 & 5-Negative & 4.7 \\
\hline \multicolumn{2}{|c|}{ Mean [SD] $1.58[1.44]^{b}$} & \multicolumn{2}{|c|}{ Mean [SD] $1.25[1.34]^{\mathrm{b}}$} \\
\hline 0-Positive & 66.3 & 0 -Positive & 72.5 \\
\hline 1 & 20.6 & 1 & 18.1 \\
\hline 2 & 9.5 & 2 & 7.2 \\
\hline 3 & 2.0 & 3 & 1.2 \\
\hline 4 & 0.6 & 4 & 0.4 \\
\hline 5-Negative & 1.0 & 5-Negative & 0.6 \\
\hline \multicolumn{2}{|c|}{ Mean [SD] $0.527[0.907]^{b}$} & \multicolumn{2}{|c|}{ Mean $[S D] 0.405[0.787]^{b}$} \\
\hline \multicolumn{2}{|c|}{ Mean [SD] $82.1[84.5]^{\mathrm{b}}$} & \multicolumn{2}{|c|}{ Mean [SD] $86.0[85.4]^{\mathrm{b}}$} \\
\hline \multirow{6}{*}{\multicolumn{2}{|c|}{ Not applicable ${ }^{d}$}} & 0-Positive & 54.9 \\
\hline & & 1 & 21.8 \\
\hline & & 2 & 15.0 \\
\hline & & 3 & 3.9 \\
\hline & & 4 & 1.8 \\
\hline & & 5-Negative & 2.7 \\
\hline
\end{tabular}

${ }^{a}$ Number of respondents varies because of item nonresponse.

bStatistical significance of difference between pre-intervention and post-intervention $\mathrm{P}<0.001$ using t-test for paired samples.

${ }^{c}$ Represents sum of attitudinal items (0-15, with 0 being most positive) converted to a 0-100 scale.

dS12 was a satisfaction question in the post-intervention survey only.

\section{DISCLOSURES}

This study was funded by sanofi-aventis to support the production of posters, activity books, and learning materials used in the presentations. Horizon Blue Cross Blue Shield of New Jersey provided a project manager. In addition, the Horizon BCBSNJ communication and pharmacy departments created the posters and activity books. Rutgers students and faculty were involved in teaching the elementary school students.

Jan collected the data and created the study concept and design with the assistance of Bellman and interpreted the data with the assistance of Arnold. All of the authors participated in writing the manuscript, and Jan performed the bulk of the revisions.

\section{REFERENCES}

1. U.S. Department of Health and Human Services, Centers for Disease and Prevention, National Center for Health Statistics. Health, United States, 2006 with chartbook on trends in the health of Americans. Available at: http://www.cdc.gov/nchs/data/hus/hus06.pdf. Accessed May 9, 2009.
2. Ogden CL, Carroll MD, Flegal KM. High body mass index for age among US children and adolescents, 2003-2006. JAMA. 2008;299(20):2401-05.

3. Flegal KM, Wei R, Ogden C. Weight-for-stature compared with body mass index-for-age growth charts for the United States from the Centers for Disease Control and Prevention. Am J Clin Nutr. 2002;75(4):761-66.

4. Koplan JP, Liverman CT, Kraak VI, eds. Preventing Childhood Obesity: Health in the Balance. Washington, DC: National Academies Press; 2005.

5. Freedman DS, Dietz WH, Srinavasan SR, Berenson GS. The relation of overweight to cardiovascular risk factors among children and adolescents: The Bogalusa Heart Study. Pediatrics. 1999;103(6 Pt1):1175-82.

6. Nafiu OO, Reynolds PI, Bamgbade OA, Tremper KK, Welch K, Kasa-Vubu JZ. Childhood body mass index and perioperative complications. Pediatr Anaesth. 2007;15:426-30.

7. Lee J, Herman WH, McPheeters ML, Gurney JG. An epidemiologic profile of children with diabetes in the U.S. Diabetes Care. 2006;29(2):420-21. 


\section{Shape It Up: A School-Based Education Program to Promote Healthy Eating and Exercise Developed by a Health Plan in Collaboration With a College of Pharmacy}

8. Whetstone LM, Morrissey SL, Cummings DM. Children at risk: the association between perceived weight status and suicidal thoughts and attempts in middle school youth. J Sch Health. 2007;77(2):59-66.

9. Schwimmer JB, Burwinkle TM, Varni JW. Health-related quality of life of severely obese children and adolescents. JAMA. 2003;289(14):1813-19.

10. Whitaker RC, Wright JA, Pepe MS, Siedel KD, Dietz WH. Predicting obesity in young adulthood from childhood and parental obesity. N Engl J Med. 1997;337(13):869-73.

11. Office of the Surgeon General. Overweight in children and adolescents: the problem of overweight in children and adolescents. Department of Health and Human Services Fact Sheet. Available at: http://www.surgeongeneral.gov/topics/obesity/calltoaction/fact_adolescents.htm. Accessed April $15,2009$.

12. U.S. Department of Health and Human Services. The Surgeon General's call to action to prevent and decrease overweight and obesity. Available at:

http://www.surgeongeneral.gov/topics/obesity/calltoaction/CalltoAction.pdf. Accessed April 15, 2009

13. Finkelstein EA, Fiebelkorn IC, Wang G. National medical spending attributable to overweight and obesity: how much, and who's paying? Health Aff (Millwood). 2003;(Suppl Web Exclusives):W3-219-26. Available at: http:// content.healthaffairs.org/cgi/content/full/hlthaff.w3.219vl/DCl. Accessed April 15, 2009

14. Wang G, Dietz WH. Economic burden of obesity in youths aged 6 to 17 years: 1979-1999. Pediatrics. 2002;109(5):E81. Available at: http://pediatrics. aappublications.org/cgi/content/full/109/5/e81. Accessed April 15, 2009.

15. Wang Y, Beydoun MA, Liang L, Caballero B, Kumanyika SK. Will all Americans become overweight or obese? estimating the progression and cost of the US obesity epidemic. Obesity (Silver Spring). 2008;16(10):2323-30. Available at: http://www.nature.com/oby/journal/v16/n10/pdf/oby200835la. pdf. Accessed April 15, 2009.

16. Nielsen SJ, Popkin BM. Patterns and trends in food portion sizes 19771998. JAMA. 2003;289(4):450-53.

17. Sebastian R, Cleveland L, Goldman J, Moshfegh A. Changes over 25 years in the dietary intakes of children 6-19 years (abstract). FASEB J. 2005;19(4):A87. Available at: http://www.ars.usda.gov/research/publications/ publications.htm?SEQ_NO_115=171361. Accessed April 9, 2009.

18. Bowman SA, Gortmaker SL, Ebbeling CB, Pereira MA, Ludwig DS Effects of fast food consumption on energy intake and diet quality among children in a national household survey. Pediatrics. 2004;13(1):112-18.

19. Enns CW, Mickle SJ, Goldman JD. Trends in food and nutrient intakes by children in the United States. Family Economics and Nutrition Review. 2002;14(2):56-68.Available at: http://www.ars.usda.gov/SP2UserFiles/ Place/12355000/pdf/fenrvl4n2p56.pdf. Accessed May 18, 2009.

20. U.S. Department of Agriculture Center for Nutrition Policy and Promotion. The food guide pyramid. Home and Garden Bulletin Number 252. August 1992. Available at: http://www.cnpp.usda.gov/Publications/ MyPyramid/OriginalFoodGuidePyramids/FGP/FGPPamphlet.pdf. Accessed May 18, 2009.

21. Enns CW, Mickle SJ, Goldman JD. Trends in food and nutrient intakes by adolescents in the United States. Family Economics and Nutrition Review. 2003;15(2):15-27.

22. Eaton DK, Kann L, Kinchen S, et al. Youth risk behavior surveillanceUnited States, 2005. MMWR Surveill Summ. 2006;55(5):1-108.

23. U.S. Department of Health and Human Services and U.S. Department of Agriculture. Dietary Guidelines for Americans, 2005. 6th ed. Washington, DC: U.S. Government Printing Office; January 2005. Available at: www. dietaryguidelines.gov. Accessed May 15, 2009.

24. Guenther PM, Dodd KW, Reedy J, Krebs-Smith SM. Most Americans eat much less than recommended amounts of fruits and vegetables. J Am Diet Assoc. 2006;106(9):1371-79.
25. Lorson BA, Melgar-Quinonez HR, Taylor CA. Correlates of fruit and vegetable intakes of US children. J Am Diet Assoc. 2009;109(3):474-78.

26. Cavadini C, Siega-Riz AM, Popkin BM. US adolescent food intake trends from 1965-1996. Arch Dis Child. 2000;83(1):18-24.

27. French SA, Lin BH, Guthrie JF. National trends in soft drink consumption among children and adolescents age 6 to 17 years: prevalence, amounts, and sources, 19977/78 to 1994/98. J Am Diet Assn. 2003;103(10):1326-31.

28. Block G. Foods contributing to energy intake in the US: data from NHANES III and NHANES 1999-2000. J Food Comp Anal. 2004;17(3-4):43947

29. National Association for Sport and Physical Education. Shape of the Nation Report: Status of Physical Education in the USA. Reston, VA: NASPE Stock Number 304-10331; 2006.

30. Nader PR; National Institute of Child Health and Human Development Study of Early Child Care and Youth Development Network. Frequency and intensity of activity of third grade children in physical education. Arch Pediatr Adolesc Med. 2003;157(2):185-90.

31. Duke J, Huhman M, Heitzler C. Physical activity levels among children aged 9-13 years. MMWR. 2003;52(33):785-88. Available at: http://www.cdc. gov/mmwr/preview/mmwrhtml/mm5233al.htm. Accessed May 20, 2009.

32. Rideout V, Roberts DF, Foehr UG. Generation M: Media in the Lives of 8-18 Year-olds. Menlo Park, CA: Kaiser Family Foundation; 2005. Available at: http://www.kff.org/entmedia/upload/Executive-Summary-Generation-MMedia-in-the-Lives-of-8-18-Year-olds.pdf. Accessed April 15, 2009.

33. Henry J. Kaiser Family Foundation. Issue brief: the role of media in childhood obesity. February 2004. Available at: http://www.kff.org/entmedia/upload/The-Role-Of-Media-in-Childhood-Obesity.pdf. Accessed April 15, 2009.

34. Story M, Kaphingst K, French S. The role of schools in obesity prevention. Future Child. 2006;16(1):109-42.

35. Institute of Medicine. Report Brief. Childhood Obesity: Health in the Balance. Washington DC: National Academies Press; 2004. Available at: http://www.iom.edu/Object.File/Master/25/858/Childhood\%20Obesity\%20 4-pager-fix\%20for\%20web\%20pdf. Accessed April 15, 2009.

36. Wong DL, Hockenberry-Eaton M, Wilson D, Winkelstein M, Schwartz P, Wong's Essentials of Pediatric Nursing. 6th ed. St. Louis, MO: Mosby; 2001.

37. Farr JN, Jenkins JJ, Paterson DG. Simplification of Flesch Reading Ease Formula, J Appl Psychol. 1951;35(5):333-37.

38. Gantz W, Schwartz N, Angelini JR, Rideout V. Food for Thought: Television Food Advertising to Children in the United States. Menlo Park, CA: Kaiser Family Foundation; 2007. Available at: http://www.kff.org/entmedia/7618. cfm. Accessed May 14, 2009.

39. Robert Wood Johnson Foundation/American Heart Association. A Nation at Risk: Obesity in the United States. A Statistical Sourcebook. 2005. Available at: http://www.rwjf.org/files/publications/other/AH_NationAtRisk.pdf. Accessed April 15, 2009.

40. Bandura A. Self-Efficacy: The Exercise of Control. New York: Macmillan; 1997.

41. Walker WA, Humphries C. Eat, Play and Be Healthy, The Harvard Medical School Guide to Healthy Eating for Kids. New York: McGraw-Hill; 2005.

42. Westenhoefer J. Establishing dietary habits during childhood for longterm weight control. Ann Nutr Metab. 2002;46(Suppl 1):S18-S23.

43. Lobstein $T$. The prevention of obesity in childhood and adolescence. In: Bray GA, Bouchard C, eds. Handbook of Clinical Obesity: Clinical Applications. New York: Marcel Dekker; 2004

44. Reilly JJ, Dorosty AR, Emmett PM. Prevalence of overweight and obesity in British children: cohort study. BMJ. 1999;319(7216):1039. 
45. Kavey RE, Daniels SR, Lauer PM, Atkins DL, Hayman LL, Taubert K. American Heart Association guidelines for primary prevention of atherosclerotic cardiovascular disease beginning in childhood. Circulation. 2003;107(11):1562-66.

46. Gee S. A pound of prevention is worth a ton of cure. Permanente Journal. 2003;7(3):9-10. Available at: http://xnet.kp.org/permanentejournal/sum03/ pound.html. Accessed May 8, 2009.

47. Must A, Naumova EN, Phillips SM, Blum M, Dawson-Hughes B, Rand WM. Childhood overweight and maturational timing in the development of adult overweight and fatness: the Newton Girls Study and its follow up. Pediatrics. 2005;116(3):620-27.

48. Ogden CL, Troiano RP, Briefel RR, Kuczmarski RJ, Flegal KM, Johnson CL. Prevalence of overweight among preschool children in the United States, 1971 through 1994. Pediatrics. 1997;99(4):E1.

49. Summerbell CD. The identification of effective programs to prevent and treat overweight preschool children. Obesity (Silver Spring). 2007;15(6):134112.

50. McLeroy KR, Bibeau D, Steckler A, Glanz K. An ecological perspective on health promotion programs. Health Educ Q. 1988;15(4):351-77.
51. Ebbeling CB, Pawlak DB, Ludwig DS. Childhood obesity: public-health crisis, common sense cure. Lancet. 2002;360(9331):473-82.

52. Heithoff KA, Cuffel BJ, Kennedy S, Peters J. The association between body mass and health care expenditures. Clin Ther. 1997;19(4):811-20.

53. Yoon EY, Davis MM, Rocchini A, Kershaw D, Freed GL. Medical management of children with primary hypertension by pediatric subspecialists Pediatr Nephrol. 2009;24(1):147-53.

54. Hale DE, Kiess W. Insulins and oral hypoglycemic medications. Pediatr Endocrinol Rev. 2004;2( Suppl 1):S153-S62.

55. Colditz GA. Economic costs of obesity and inactivity. Med Sci Sports Exerc. 1999;31(Suppl 11): S663-S667.

56. Levin BE. The drive to regain is mainly in the brain. Am J Physiol Regul Integr Comp Physiol. 2004;287(6):R1297-300. Available at: http://ajpregu. physiology.org/cgi/content/full/287/6/R1297. Accessed April 15, 2009.

57. U.S. Department of Health and Human Services. Prevention makes common "cents." 2003. Available at: http://aspe.hhs.gov/health/ prevention/\#N_160. Accessed April 15, 2009.

58. Glanz K, Rimer BK, Lewis FM. Health Education and Health Education: Theory, Research and Practice. San Francisco: Jossey-Bass; 2002. 